\title{
Expression of fra(10)(q25) in peripheral blood bone marrow in familial neutropenia
}

\author{
J A HOLMES AND P W THOMPSON \\ From the Department of Haematology and Institute of Medical Genetics, University of Wales College of \\ Medicine, Cardiff CF4 $4 X N$.
}

SUMMARY We report on the expression of fra(10)(q25) in a mother and daughter with familial chronic neutropenia. Differences in expression of the fragile site in bone marrow cells compared with peripheral blood lymphocytes were observed. Short term bone marrow cultures in complete ô medium showed high levels of spontaneous expression, whereas in 72 hour stimulated blood $\dot{\sim}$ cultures it was virtually absent. There were also differences in the types of lesions found; $\mathfrak{\omega}_{\infty}$ chromosome type lesions predominated in the marrow and chromatid type in the blood.의 Apparent folate sensitivity of the fra(10)(q25) is also discussed.

The heritable fragile site at $10 \mathrm{q} 25$ is polymorphic and has been well documented in peripheral blood lymphocytes and skin fibroblasts. ${ }^{1-3}$ There are single reports of its expression in bone marrow cells ${ }^{4}$ and human sperm chromosomes. ${ }^{5}$ Cytogenetic manifestation of the site is normally dependent on the addition of bromodeoxyuridine (BrdU) or bromodeoxycytidine (BrdC) to the culture medium, ${ }^{267}$ although there are a number of reports of spontaneous expression. 1489

We report on the expression of $\operatorname{fra}(10)(\mathrm{q} 25)$ in peripheral blood lymphocytes and bone marrow cells in a mother and daughter with familial chronic neutropenia.

\section{Clinical comment}

Benign familial neutropenia is a rare but well recognised condition with autosomal dominant inheritance. Affected subjects usually have a normal lifespan, but tend to have recurrent mouth ulceration, furuncles, and frequent respiratory tract infections. Neutropenia is constant but not severe with cell counts varying between 1 and $2 \times 10^{9} / 1$. Bone marrow myeloid cells are usually morphologically normal but there may be a maturation arrest at the metamyelocyte stage and a reduced myeloid/erythroid ratio. ${ }^{10}$ Colony forming ability by granulocyte progenitors is unaffected. ${ }^{11}$ Neutrophil release in response to intravenous hydrocortisone is reduced. ${ }^{12}$ This has been suggested as a diagnostic test to distinguish this condition from other forms of neutropenia.

Received for publication 12 August 1986

Revised version accepted for publication 29 April 1987.
We describe here a family in which a mother and $\overrightarrow{0}$ daughter, the two affected subjects (II.4 and III.2, $\infty$ fig 1), have a constant mild neutropenia (table 1), an autosomal dominant pattern of inheritance, and appropriate clinical features. Bone marrow morphology and colony forming ability are compatible with the criteria described above.

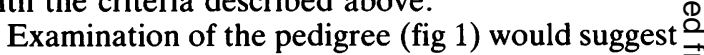
that the mother (II.4) has acquired this condition as a result of 'de novo' mutation with subsequent inheritance by her daughter (III.2). All other living family members shown in fig 1 have been investi-gated and show neither clinical nor haematological evidence of chronic neutropenia.
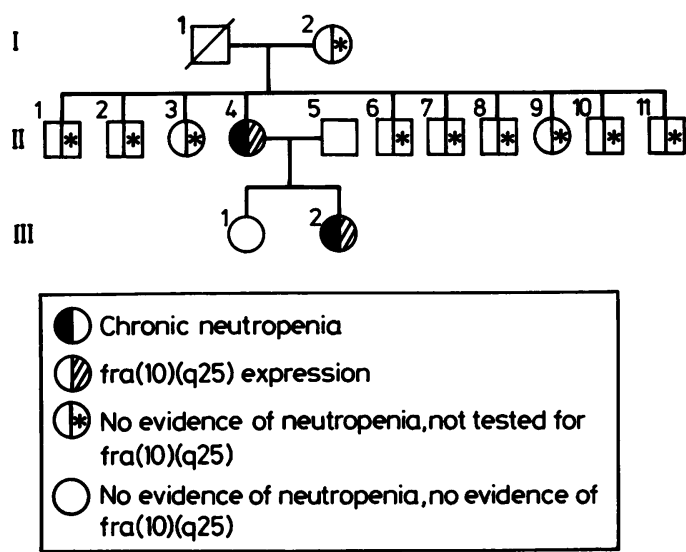

FIG 1 Family pedigree. 
TABLE 1 Haematological data.

\begin{tabular}{lll}
\hline & $\begin{array}{l}\text { Mean total WBC } \\
\left(\times 10^{9} / l\right)\end{array}$ & $\begin{array}{l}\text { Mean neutrophil count } \\
\left(\times 10^{9} / l\right)\end{array}$ \\
\hline II.4 & 2.9 & $1 \cdot 2$ \\
III.2 & 3.4 & $1 \cdot 5$ \\
III.1 & 4.3 & $2 \cdot 3$ \\
I.2 & $5 \cdot 0$ & $2 \cdot 6$ \\
II.5 & $8 \cdot 1$ & 4.4 \\
\hline
\end{tabular}

\section{Materials and methods}

Bone marrow aspirate and peripheral blood samples were obtained from the affected mother and daughter, while blood samples alone were received from the father and unaffected daughter. Samples of bone marrow aspirate were cultured at $37^{\circ} \mathrm{C}$ for 24 hours in McCoy's 5A medium plus $20 \%$ fetal calf serum (FCS) with and without a methotrexate (MTX) $\left(10^{-7} \mathrm{~mol} / \mathrm{l}\right)$ block and thymidine (THY) $\left(10^{-5}\right.$ $\mathrm{mol} / \mathrm{l}$ ) release. Seventy-two hour PHA stimulated peripheral blood lymphocyte cultures were established using McCoy's 5A plus 20\% FCS with and without a MTX synchronisation and in medium 199 without serum. The effect on fra(10)(q25) expression by the addition of $\mathrm{BrdC}$ at various times before harvest and at various concentrations was studied in McCoy's 5A medium. The effect of culture time on fra(10)(q25) expression was also studied in McCoy's 5A. Unless stated BrdC was added eight hours before harvest. For the affected patients two blood samples were received three months apart and the culture conditions indicated in table 2 established each time. The culture conditions described in table 3 and fig 2 were established once only. From each culture, on both occasions, 100 metaphase spreads were sequentially analysed for the presence of fragile $10 \mathrm{q} 25$, initially unbanded and then by trypsin $\mathrm{G}$ banding.

\section{Results}

Cytogenetic analysis of bone marrow and peripheral blood samples of the mother and affected daughter showed the presence of the fragile site at $10 \mathrm{q} 25$; their karyotypes were normal in other respects. The father and unaffected daughter had normal karyotypes with no evidence of fragile sites. Fig 3 illustrates the appearance of the fragile site in the bone marrow cultures of the mother.

Table 2 shows the frequency of types of lesions at $10 \mathrm{q} 25$ in the cultures examined in this report compared with a study by Sutherland et al. ${ }^{6}$ No marked differences in expression were found for the repeat cultures over the three month time interval.

The fra(10)(q25) expression in the bone marrow of the patients was similar, with both showing spontaneous expression in 24 hour unstimulated cultures. In the unsynchronised cultures, the expression in mother and daughter was $21 \%$ and $22 \%$ respectively, while MTX synchronisation resulted in increased levels of $57 \%$ and $44 \%$. The majority of lesions were of the chromosome type, and there was also a high number of the rare manifestations of the fragile site, deletions, deletions with acentric fragments, and triradial figures.

TABLE 2 Frequency of types of lesions at 10q25.

\begin{tabular}{|c|c|c|c|c|c|c|}
\hline \multirow{2}{*}{$\begin{array}{l}\text { Specimen and } \\
\text { culture conditions }\end{array}$} & \multicolumn{6}{|c|}{ Frequency of types of lesions (\%) } \\
\hline & Chromatid & Chromosome & $\begin{array}{l}\text { Deletion } \\
\text { and acentric }\end{array}$ & Deletion & Triradial & Normal \\
\hline \multicolumn{7}{|l|}{ Mother-bone marrow } \\
\hline McCoy's 5A & 6 & 9 & 0 & 3 & 3 & 79 \\
\hline$+\mathrm{MTX}$ & 13 & 24 & 7 & 9 & 4 & 43 \\
\hline \multicolumn{7}{|c|}{ Daughter-bone marrow } \\
\hline McCoy's & 4 & 13 & 5 & 0 & 0 & 78 \\
\hline +MTX & 10 & 22 & 6 & 4 & 2 & 56 \\
\hline \multicolumn{7}{|l|}{ Mother-blood } \\
\hline McCoy's & 0 & 0 & 0 & 0 & 0 & 100 \\
\hline$+\mathrm{MTX}$ & 1.5 & $2 \cdot 5$ & 0 & 0.5 & 0.5 & 95 \\
\hline$+100 \mathrm{mg} / \mathrm{l} \mathrm{BrdC}$ & 9 & 5 & 0 & 0 & 0 & 86 \\
\hline$+50 \mathrm{mg} / 1 \mathrm{BrdC}$ & 12 & 3 & 0 & 0 & 0 & 85 \\
\hline$+10 \mathrm{mg} / \mathrm{l} \mathrm{BrdC}$ & 1 & 3 & 0 & 0 & 0 & 96 \\
\hline 199 & 2 & 3 & 0 & 0 & 0 & 95 \\
\hline \multicolumn{7}{|l|}{ Daughter-blood } \\
\hline McCoy's & 0.5 & 0 & 0 & 0 & 0 & 99.5 \\
\hline$+\mathrm{MTX}$ & 1 & 0.5 & 0 & 0 & 0 & $98 \cdot 5$ \\
\hline$+100 \mathrm{mg} / \mathrm{l} \mathrm{BrdC}$ & 32 & 14 & 0 & 0 & 0 & 54 \\
\hline$+50 \mathrm{mg} / \mathrm{l} \mathrm{BrdC}$ & 28 & 10 & 0 & 0 & 0 & 62 \\
\hline$+10 \mathrm{mg} / \mathrm{l} \mathrm{BrdC}$ & $8 \cdot 5$ & 2 & 0 & 0 & 0 & 89.5 \\
\hline 199 & 4 & 2 & 1 & 0 & 0 & 93 \\
\hline \multicolumn{7}{|l|}{ Sutherland et $a t^{t}$} \\
\hline (10 cases) & 31 & 11 & 2 & 3 & & 53 \\
\hline
\end{tabular}


TABLE 3 Effect of culture time on fra(10)(q25) expression.

\begin{tabular}{|c|c|c|c|c|c|c|c|}
\hline \multirow{2}{*}{$\begin{array}{l}\text { Specimen and } \\
\text { culture conditions }\end{array}$} & \multicolumn{6}{|c|}{ Frequency of types of lesions $(\%)$} & 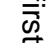 \\
\hline & Chromatid & Chromosome & $\begin{array}{l}\text { Deletion } \\
\text { and acentric }\end{array}$ & Deletion & Triradial & Normal & 음 \\
\hline $\begin{array}{l}\text { Mother-blood } 48 \text { hour } \\
\text { McCoy's 5A }\end{array}$ & ) & 0 & 0 & 0 & 0 & 100 & $\frac{\omega}{\mathbb{D}}$ \\
\hline$+100 \mathrm{mg} / \mathrm{l} \mathrm{BrdC}$ & 11 & 6 & 3 & 0 & 0 & 80 & \\
\hline$+50 \mathrm{mg} / \mathrm{l} \mathrm{BrdC}$ & 5 & 4 & 2 & 0 & 0 & 89 & 心 \\
\hline \multicolumn{8}{|l|}{72 hour } \\
\hline McCoy's 5A & 0 & () & 0 & 0 & 0 & 100 & $\overline{0}$ \\
\hline$+100 \mathrm{mg} / \mathrm{l} \mathrm{BrdC}$ & 17 & 8 & 0 & 0 & 0 & 75 & 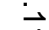 \\
\hline$+50 \mathrm{mg} / \mathrm{l} \mathrm{BrdC}$ & 16 & 8 & 1 & 0 & 0 & 75 & 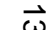 \\
\hline \multicolumn{7}{|l|}{96 hour } & (4) \\
\hline McCoy's 5A & 0 & () & 0 & 0 & 0 & 100 & 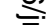 \\
\hline$+100 \mathrm{mg} / 1 \mathrm{BrdC}$ & 30 & 7 & 0 & 0 & 0 & 63 & 3 \\
\hline$+50 \mathrm{mg} / \mathrm{BrdC}$ & 28 & 8 & 0 & 0 & 0 & 64 & Q \\
\hline $\begin{array}{l}\text { Daughter-blood } 48 \text { hour } \\
\text { McCoy`s 5A }\end{array}$ & () & () & 0 & 0 & 0 & 100 & N \\
\hline$+100 \mathrm{mg} / 1 \mathrm{BrdC}$ & 8 & 7 & 1 & 0 & 0 & 84 & 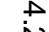 \\
\hline$+50 \mathrm{mg} / \mathrm{l} \mathrm{BrdC}$ & 8 & 7 & 0 & 0 & 0 & 85 & N \\
\hline \multicolumn{7}{|l|}{72 hour } & $\infty$ \\
\hline McCoys 5A & () & 0 & () & 0 & 0 & 100 & 0 \\
\hline$+100 \mathrm{mg} / 1 \mathrm{BrdC}$ & 44 & 12 & 0 & 0 & 0 & 44 & 与 \\
\hline$+50 \mathrm{mg} / \mathrm{l} \mathrm{BrdC}$ & 46 & 6 & 0 & 0 & 0 & 48 & - \\
\hline \multirow{2}{*}{\multicolumn{7}{|c|}{96 hour }} & \\
\hline McCoy's 5A & & & & & & 100 & 우 \\
\hline$+100 \mathrm{mg} / \mathrm{l} \mathrm{BrdC}$ & 51 & 12 & 0 & 0 & 0 & 37 & 三. \\
\hline$+50 \mathrm{mg} / \mathrm{l} \mathrm{BrdC}$ & 43 & 16 & 0 & 0 & 0 & 41 & \\
\hline
\end{tabular}

Peripheral lymphocytes of the mother cultured in complete media without synchronisation failed to express the fra(10)(q25) and only 1/200 cells showed it in the daughter. MTX synchronisation resulted in low levels of expression at $5 \%$ and $1 \cdot 5 \%$. Cultures grown in low folate medium 199 showed expression of $5 \%$ and $7 \%$.

As with all reported cases, with the exception of the report of Petit and Fryns, ${ }^{9}$ the fra(10)(q25) in

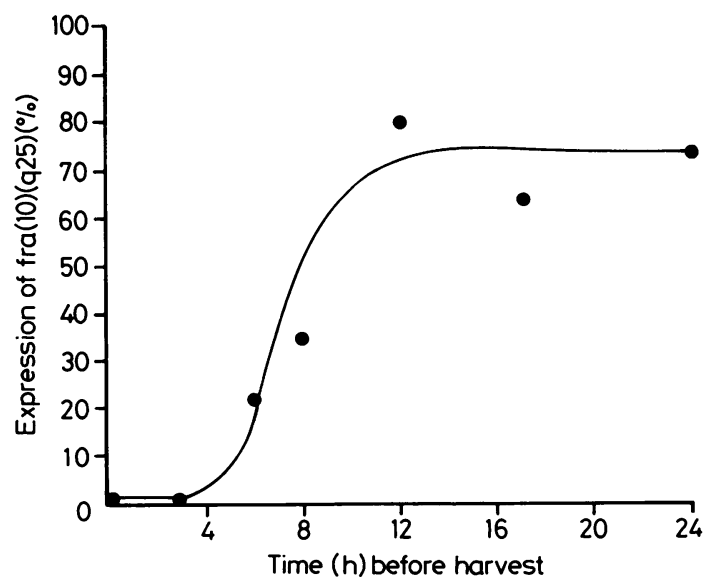

FIG 2 Effect of time before harvest of addition of $50 \mathrm{mg} / \mathrm{l}$ $B r d C$ on frequency of expression of $\mathrm{fra}(10)(q 25)$. this study showed sensitivity to a halogenated thymidine analogue and addition of $\mathrm{BrdC}$ to the cultures eight hours before harvest resulted in a concentration dependent expression. The major $\stackrel{\mathscr{Q}}{\mathscr{Q}}$ form of manifestation of the fragile site in peripheral blood lymphocytes was a chromatid gap or break응 and extremely few of the rarer manifestations were seen. These results are similar to those previouslyz published. ${ }^{6}$

Table 3 shows the effect of duration of culture on fra(10)(q25) expression in peripheral blood speci- $-\dot{0}$ mens of mother and daughter.

A comparison of culture time on expression of fra $(10)(q 25)$ shows that, in the presence of BrdC, an increase in the duration of culture from 72 hours too 96 hours gave a higher level of expression, while a decrease from 72 hours to 48 hours gave a lowero level of expression. No expression was seen in the absence of BrdC. Similar findings have been re- $\sigma$ ported for some of the folate sensitive fragile sites. ${ }^{13} \mathrm{~N}$ In 96 hour and 72 hour cultures chromatid lesions N predominated, but in 48 hour cultures the ratio of $\sigma$ chromatid to chromosome lesions was approximately $1: 1$

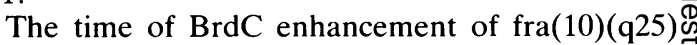
was examined in 72 hour cultures of peripheral ${ }_{0}$ blood from the daughter and the results are showno in fig 3. The presence of $50 \mathrm{mg} / \mathrm{l} \mathrm{BrdC}$ in the culture medium 24 to 12 hours before harvest resulted in a $\vec{\Phi}$ high level of expression of approximately $70 \% .2$ After this time addition of $\mathrm{BrdC}$ gave reduced levels 


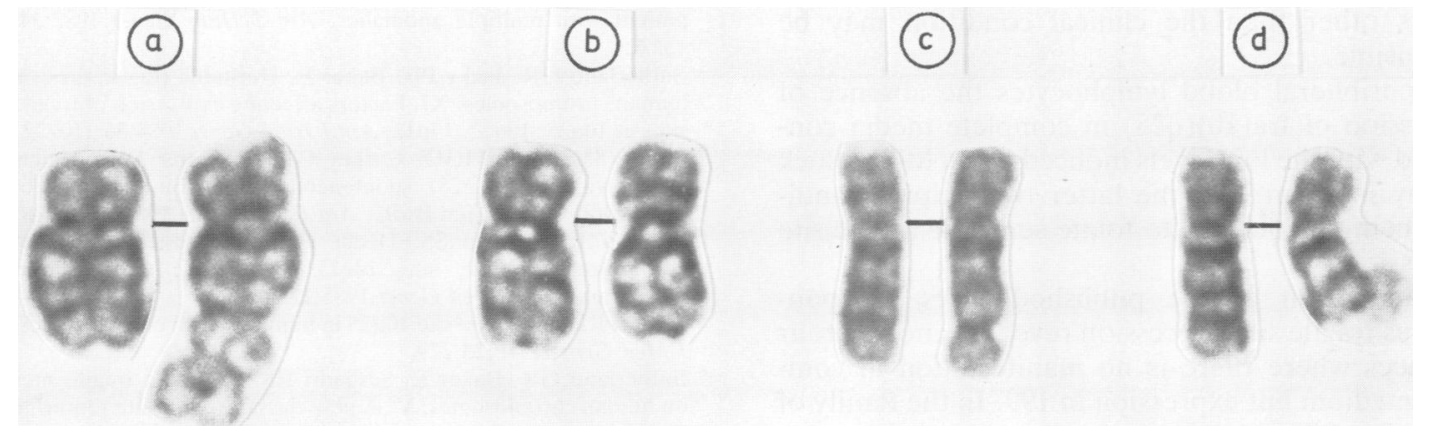

of expression until no effect was observed three hours before harvest.

\section{Discussion}

There are only five previously published studies of fragile sites in bone marrow cells. The folate sensitive sites at $2 \mathrm{q} 13$ and $\mathrm{Xq} 27$ were seen in $21 \%$ and $4 \%$ of cells respectively, ${ }^{13}{ }^{14}$ the two reports of the distamycin $A$ inducible fragile site at $16 \mathrm{q} 22$ showed levels of expression of $5 \%$ and $4 \%,{ }^{15} 16$ and the $\mathrm{BrdU}$ requiring site at $10 \mathrm{q} 25$ was seen in $52 \%$ of cells in an unsynchronised culture and $43 \%$ in a MTX synchronised culture. ${ }^{4}$

In this report the high levels of spontaneous expression of fra(10)(q25) in the bone marrow cells of both mother and daughter were similar to the values of Morgan et al. ${ }^{4}$ Expression of fra(10)(q25) in peripheral blood lymphocytes correlated well with published findings in its response to $\mathrm{BrdC}$ and in the types of lesion found.

A comparison of fra(10)(q25) expression in bone marrow and peripheral blood shows two major differences; firstly, high levels of spontaneous expression in complete medium in the former and its virtual absence in the latter, and secondly the predominance of chromosome type lesions in the marrow and chromatid type lesions in the blood.

There are a number of possible explanations for the differences.

(1) They may reflect the cell types examined. The blood cultures were stimulated by PHA, a T cell mitogen, and the mitoses examined would mainly represent fra(10)(q25) in the peripheral blood $T$ lymphocyte populations, whereas in unstimulated bone marrow cultures a variety of cell types would have been dividing and analysed for fra(10)(q25).

(2) Tissue specificity may be a factor in expression, environmental conditions in the bone marrow predisposing more to expression than those found in blood.
(3) Expression may be dependent on the number of divisions a cell has passed through. Bone marrow cells are continuously dividing and will contain metaphases that have been through differing numbers of cell cycles. It is possible that a chromatid lesion in one division may become a chromosome lesion in the next or vice versa. In stimulated peripheral blood the number of divisions a cell has passed through will depend on the length of culture. Table 3 shows that with addition of BrdC for the last eight hours, the 72 hour and 96 hour cultures showed no differences in the types of lesion expressed, while in the 48 hour culture the numbers of chromatid and chromosome lesions were approximately equal.

To test if $\mathrm{BrdC}$ induced lesions altered with an increasing number of cell cycles, $5 \mathrm{mg} / \mathrm{l} \mathrm{BrdC}$ was added at initiation of 48 hour and 72 hour cultures (data not shown). The proportion of chromatid to chromosome type lesions was similar to those found when BrdC was added for the last eight hours of culture only, being $2.5 \%$ and $2 \%$ in the 48 hour and $7 \%$ and $2.5 \%$ in the 72 hour respectively. These data suggest that for stimulated peripheral blood, although 48 hour cultures showed an equal number of chromatid and chromosome lesions, after this time chromatid lesions predominated irrespective of the number of divisions the cell has been through.

(4) A further explanation may be that the clinical condition is influencing expression and that increased levels of $\operatorname{fra}(10)(\mathrm{q} 25)$ are in some way related to the myeloid maturation defect in the bone marrow. We have been unable to study other family members for fragile site expression and are consequently unable to determine the exact association between $\mathrm{fra}(10)(\mathrm{q} 25)$ in chronic neutropenia. Morgan $\mathrm{et} \mathrm{al}^{4}$ proposed that malignancy appeared to act as a factor enhancing expression of fra(10)(q25). However, in the two patients studied here the disorder is chronic and benign which suggests that 
factors other than the clinical condition may be responsible.

In peripheral blood lymphocytes the absence of expression of fra $(10)(\mathrm{q} 25)$ in complete media contrasted with the low levels induced by an MTX block and by medium 199, the latter two culture conditions being favourable to folate sensitive fragile site expression.

Examination of the published cases of spontaneous fragile site expression revealed another four instances where there is no manifestation in complete medium but expression in 199. In the family of Taylor and Bundey, ${ }^{8}$ the brother showed no expression in Ham's F10 but 4\% expression in 199. In the study of Ledbetter et $\mathrm{l}^{1}$ the father failed to show the fra(10)(q25) in RPMI but $2 \%$ of cells in 199 were positive. Finally, in the family of Gollin $e t a l^{3}$ the aunt and sister did not express in RPMI but showed levels of $12 \%$ and $10 \%$ respectively in 199 .

These results together with the present findings suggest that the fragile site at $10 \mathrm{q} 25$ shows some degree of folate sensitivity and its classification should be redefined.

The contrasting results on fra(10)(q25) expression between bone marrow cells and peripheral blood lymphocytes indicate that studies on tissues other than lymphocytes may help to elucidate further the nature of fragile sites.

We wish to acknowledge Professor K M Laurence, Professor Allan Jacobs, and Mr S H Roberts for their helpful discussion, and all the family who kindly cooperated in this study.

\section{References \\ ' Ledbetter DH, Bock HO, Caskey CT. Cytogenetic studies of a BrdU-sensitive but not BrdU-dependent fra(10)(q25) in a}

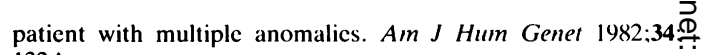
$132 \mathrm{~A}$.

2 Sutherland GR, Jacky PB, Baker E. Heritable fragile sites ov human chromosomes. XI. Factors affecting expression of fragils sites at 10q25,16q22,17p12. Am J Hum Genet 1984:36:110-22.C

${ }^{3}$ Gollin SM. Bock HGO, Caskey CT, Ledbetter DH. A new family with fra(10)(q25): spontancous expression and $100 \%$ of expression with 100 $\mu \mathrm{m}$ BrdU. Am J Med Genet 1985:21:643-8.

+ Morgan R, Morgan SS, Hecht F. Enhanced expression of chromosome fragile sitc 10q25 in chronic myclogenouङ leukaemia. Am J Med Genet 1985:21:347-50.

5 Martin RH. A fragile site $10 \mathrm{q} 25$ in human sperm chromosomes. J Med Genet 1986:23:279.

- Sutherland GR, Baker E. Seshadri RS. Heritable fragile sites on human chromosomes. V. A new class of fragile site requiring BrdU for expression. Am J Hum Genet 1980;32:542-8.

7 Scheres JMJC, Hustinx TWJ. Heritable fragile sites an $\overline{\mathscr{Q}}$ lymphocyte culture medium containing BrdU. Am J Hum Gene 1980:32:628-9.

* Taylor AMR, Bundey S. Spontancous expression of tha chromosome fragile site fra(10)(q25). Am J Hum Genet 1983;35 123-5.

9 Petit P. Fryns JP. Expression of fragile sitc at 10q25 in normab culture conditions. Am J Hum Genet 1983:35:126-7.

10 Cutting HO, Lang JE. Familial benign chronic neutropeniad Ann Intern Med 1964:61:876-87.

1 Minty M, Sachs L. Normal granulocytic colony formation cells in the bone marrow of Yememite Jews with genetic neutroe penia. Blood 1973:41:745-52.

12 Schocnfeld Y, Modan M, Berliner S, et al. The mechanism of benign hereditary neutropenia. Arch Intern Med 1982;142? 797-9.

13 Sutherland GR. Hecht F. Fragile sites on human chromosomes New York: Oxford University Press, 1985.

$14 \mathrm{del}$ Pozo BC. Millard PR. Demonstration of the fra $(X)$ i lymphocytes, fibroblasts and bone marrow in a patient with testicular tumour. J Med Genet 1983;20:225-7.

15 Magenis RE, Hecht F, Lovrien EW. Heritable fragile sites or chromosome 16: probablc localization of haptoglobin locus in man. Science 1970):170:85-7.

16 Haas OA, Nacheva E, Schwarzmeicr JD. Non involvement chromosome 16 in karyotype cvolution of acute mycloia. lcukacmia in a paticnt with a heritable fragile sitc on $16 q 223$ Cancer Genet Cytogenet 1985;17:1-12.

Correspondence and requests for reprints to $\operatorname{Dr} \mathrm{J} A$. Holmes, Department of Haematology, Universits Hospital of Wales, Heath Park, Cardiff CF4 4XWß 